\title{
THE SOURCES OF INNERVATION OF THE AORTIC ARCH AND THORACIC AORTA IN HUMAN FETUSES
}

\author{
Galyna Ya. STELMAKH ${ }^{1}$, Tatiana V. KHMARA ${ }^{1 凶}$, Inna V. LUKASHEVYCH ${ }^{1}$, \\ Volodymyr V. VIZNIUK ${ }^{1}$, Iryna D. KIIUN ${ }^{1}$, Ruslan P. KNUT ${ }^{1}$
}

${ }^{1}$ Bukovinian State Medical University, Chernivtsi, Ukraine

Received 02 Sept 2021, Accepted 17 Oct 2021

htpp://doi.org/10.31688/ABMU.2021.56.4.11

\begin{abstract}
Introduction. The development of angiosurgery requires the morphologists to clarify in more details the topographic anatomical peculiarities of arterial vessels, considering their morphogenesis, peculiarities of innervation, age and individual anatomical variability in different periods of human ontogenesis.
\end{abstract}

The objective of the study was to clarify the sources and peculiarities of innervation of the aortic arch and thoracic aorta in human fetuses.

Materials and methods. The study was performed on 36 preparations of human fetuses of 81.0-375.0 $\mathrm{mm}$ of parietal-coccygeal length using a combination of methods, such as macro-microscopic preparation, vascular injection, application staining, making of 3D reconstruction models, morphometry.

Results. The sources of innervation of the aortic arch in human fetuses are the cervical cardiac branches of the vagus nerve, the cervical cardiac nerve and the single branches of the upper three or four thoracic ganglia of the sympathetic trunks. The innervation of the thoracic aorta is performed by the branches of the thoracic aortic plexus, collateral trunk and also the branches of the paraaortic plexus, which is located between the sympathetic trunk and the thoracic aorta on both sides. From each thoracic ganglion and internodal branch of the sympathetic trunks depart 2-6 branches, some of which go to the thoracic aorta

\section{Résumé}

Sources d'innervation de l'arc aortique et de l'aorte thoracique dans le foetus humain

Introduction. Le développement de l'angiochirurgie mène les morphologues à clarifier plus en détail les caractéristiques topographiques et anatomiques des vaisseaux artériels, en tenant compte de leur morphogenèse, des caractéristiques d'innervation, de l'âge et de la variabilité anatomique individuelle à différentes périodes de l'ontogenèse humaine.

L'objectif de l'étude est d'analyser les sources et les caractéristiques de l'innervation de l'arc aortique et de l'aorte thoracique chez les foetus humains.

Matériaux et méthodes. L'étude a été réalisée sur 36 préparations de foetus humains de 81,0 à $375,0 \mathrm{~mm}$ de longueur pariétale-coccygienne en utilisant un ensemble de méthodes : la préparation macro-microscopique, l'injection vasculaire, l'application de contraste, la réalisation de modèles de reconstruction 3D, la morphométrie.

Résultats. Les sources d'innervation de l'arc aortique chez les foetus humains sont les branches cardiaques cervicales des nerfs vagues, les nerfs cardiaques cervicaux et les branches uniques des trois ou quatre nouds thoraciques supérieurs des troncs sympathiques. L'innervation de l'aorte thoracique est assurée par les branches du plexus aortique thoracique, le tronc 
along the posterior intercostal arteries, and the other branches are connected by connecting branches forming the collateral trunk. The vagus nerve throughout the thoracic region gives branches to the thoracic aorta with the formation of the thoracic aortic plexus.

Conclusions. In human fetuses, the paraaortic plexus is found between the right and left sympathetic trunks and the thoracic aorta, in addition to the intermediate plexus or collateral trunk. In the dynamics of the fetal period of ontogenesis, a bilateral asymmetry in the structure and formation of plexuses of the thoracic aorta is observed. At the end of the human fetal period, the number of connecting branches between the nerve branches of the paraaortic plexus increases.

Keywords: thoracic aorta, aortic arc, innervation, topography, fetus, human.

\section{INTRODUCTION}

In recent years, the attention of many scientists is focused on determination of the patterns of prenatal morphogenesis and the formation of topographic anatomical interrelations of human organs, vessels and nerves, which is important for ascertaining of morphological preconditions of the possible occurrence of anatomical variants and congenital malformations (CM). The CM incompatible with life dominate among the causes of early neonatal mortality: almost $26 \%$ of cases of perinatal and neonatal mortality are associated with congenital pathology of the child ${ }^{1}$. According to the US National Statistical Register, aortic diseases are in the top ten among the first 113 causes of death ${ }^{2}$. CM of the aorta are divided into two groups: $\mathrm{CM}$ with a predominance of aortic pathology (aortic coarctation, open arterial Botall duct), and $\mathrm{CM}$ with possible involvement of the aorta (syndromes of Ehlers-Danlos, Gordon-Overstreet, Stiller, Grandblad-Standelberg, Williams-Boyren, Goldenhar) ${ }^{3}$.

One of the current problems of the modern cardiovascular surgery is aortic aneurysm, with a mortality rate of $27.4 \%{ }^{4}$. The main causes of aortic aneurysms are atherosclerosis of the aortic wall, aortides, traumatic injury, congenital systemic connective tissue diseases (e.g., Marfan's or Ehlers-Danlos syndrome), autoimmune diseases, iatrogenic factors due collatéral, ainsi que les branches du plexus para-aortique, situé entre le tronc sympathique et l'aorte thoracique des deux côtés. De chaque nœud thoracique et branche internodale des troncs sympathiques partent 2 à 6 branches, dont certaines vont à l'aorte thoracique par les artères intercostales postérieures, et les autres branches sont reliées par des branches de connexion pour former un tronc collatéral. Les nerfs vagues dans toute la région thoracique donnent des branches à l'aorte thoracique avec la formation du plexus aortique thoracique.

Conclusions. Chez les fotus humains, le plexus para-aortique se trouve entre les troncs sympathiques droit et gauche et l'aorte thoracique en plus du plexus intermédiaire ou tronc collatéral. Dans la dynamique de la période foetale d'ontogenèse, il existe une asymétrie bilatérale dans la structure et la formation des plexus de l'aorte thoracique. À la fin de la période foetale humaine, le nombre de branches de connexion entre les branches nerveuses du plexus para-aortique augmente.

Mots-clés: aorte thoracique, arc aortique, innervation, topographie, foetus, humain.

to medical manipulations etc. Marfan's syndrome, together with other inherited connective tissue diseases, occupies the second place among the causes of aortic aneurysms $s^{5-7}$. The correction of the aortic arch pathology (aneurysm, stratification) can be performed by partial resection of the arch or its complete replacement using various techniques of reimplantation of the brachiocephalic trunk, common carotid arteries and the formation of a distal anastomosis ${ }^{8}$.

The annual number of newly detected thoracic aortic aneurysms is 3.2-3.5 cases per 100,000 population ${ }^{9}$. According to the localization, the thoracic aortic aneurysms are: ascending of arch and descending. The complications of an aortic aneurysm include stratification, rupture, internal bleeding, hypovolemic shock, thrombosis, and thromboembolism ${ }^{10}$.

The stenosis of the proximal thoracic aorta is usually called aortic coarctation. Despite the supposed simplicity of this defect, the coarctation of aorta varies considerably from anatomical and physiological points of view, clinical course and methods of treatment ${ }^{11}$.

The development of angiosurgery requires the morphologists to clarify in more details the topographic anatomical peculiarities of arterial vessels, considering their morphogenesis, peculiarities of innervation, age and individual anatomical variability in different periods of human ontogenesis ${ }^{12}$. Information about the variant anatomy of the arch 
and descending parts of the aorta is interesting not only from an anatomical point of view, but also in the embryological aspect, and allows to plan more carefully the surgical interventions. Thus, a good knowledge of the peculiarities of innervation of the arch and thoracic aorta in human fetuses has not only a theoretical importance, but also applied value for fetal surgeons.

The obJective of the STUdy was to clarify the sources and peculiarities of innervation of the arch and thoracic aorta in human fetuses.

\section{Materials AND Methods}

The study was performed on 36 preparations of human fetuses with parieto-coccygeal length (PCL) of 81.0-375.0 mm, without external signs of anatomical abnormalities or abnormalities in the development of the skeleton of the chest, organs and structures of the thoracic cavity. The clarification of the sources and ascertainment of topographic anatomical peculiarities of innervation of the arch and descending aorta, particularly of its thoracic part, during the fetal period of human ontogenesis, requires the use of adequate morphological research methods (macro-microscopic preparation, vascular injection, application staining of dissected vessels and nerves, making of 3D reconstruction models and morphometry), which allows not only to perform a high-quality scientific research and to obtain valuable results, but also to offer practical recommendations. The preparations of fetuses with weight of more than $500.0 \mathrm{~g}$ were studied directly at the Chernivtsi Regional Municipal Medical Institution "Pathological Bureau" (Ukraine). Preparations of fetuses from the morphological museum of Bukovinian State Medical University were also used for the study. The research was performed in compliance with the basic bioethical regulations of the Council of Europe Convention on Human Rights and Biomedicine (04.04.1997), the Helsinki Declaration of the World Medical Association on ethical principles of scientific medical research with human participation (1964-2013), the order of the Ministry of Health of Ukraine $\mathrm{N}^{\circ} 690$ dated 23.09.2009, and by taking into account the methodological recommendations of the Ministry of Health of Ukraine "Procedure of biological objects' extraction from deceased persons, whose bodies are liable to forensic examination and pathological study for scientific purposes" (2018). The Commission on Biomedical Ethics of Bukovinian State Medical University (Ukraine) did not find any violations of bioethical, moral and legal norms during the scientific research.

\section{Results AND discussion}

In the studied fetuses, in the innervation of the aortic arch take part the cervical cardiac branches of the right and left vagus nerve, cervical cardiac nerves and single branches from the upper 3-4 thoracic ganglia of the right and left sympathetic trunks.

Typically, the upper cervical cardiac branch from the left vagus nerve goes to the anterior surface of the left common carotid artery and divides into two branches: the medial, which reaches the aortic arch wall, and the lateral, which runs along the anterior surface of the left common carotid artery. At the site of adjacency to the aortic arch, from the left vagus nerve departs the left recurrent laryngeal nerve, which encircles the aortic arch from below and goes in the cranial direction along the lateral surface of the trachea and lies in the tracheoesophageal sulcus. In one case (fetus of $120.0 \mathrm{~mm}$ PCL) from the left vagus nerve at the level of the lower edge of the aortic arch, slightly above the beginning of the left pulmonary artery, departed the left recurrent laryngeal nerve. At the level of the aortic arch, 2-3 branches begin from the left vagus nerve, that go to the anterior surface of the root of the left lung.

In most of the studied fetuses, the upper cardiac branch from the right vagus nerve starts at the level of the lower edge of the right lobe of the thyroid gland and goes caudally to the anterior surface of the right common carotid artery. The upper cardiac branch of the right vagus nerve, slightly above the right subclavian artery, usually divides into 2-4 branches: the paramedian - to the initial part of the right common carotid artery, and 1-3 lateral branches, which go down and give branches to the shoulder-head trunk, posterior surface of the right subclavian artery or directly to the aortic arch. The right recurrent laryngeal nerve branches from the right vagus nerve at the level of crossing of the nerve with the right subclavian artery, then passes medially, encircles the lower right subclavian artery and goes up to the trachea and larynx. The lower cardiac branch from the right recurrent laryngeal nerve goes in the caudo-medial direction and takes its place on the anterior surface of the trachea.

The upper cervical cardiac nerve begins with 1-3 trunks mainly from the upper cervical ganglion, rarely from the middle cervical ganglion of the sympathetic trunk. In the area of the upper mediastinum, the right superior cervical cardiac nerve locates in front of the shoulder-head trunk, and the left cognominal nerve - more ventrally than the left common carotid artery. Then, the right and left upper cervical cardiac nerves pass to the anterior surface of 


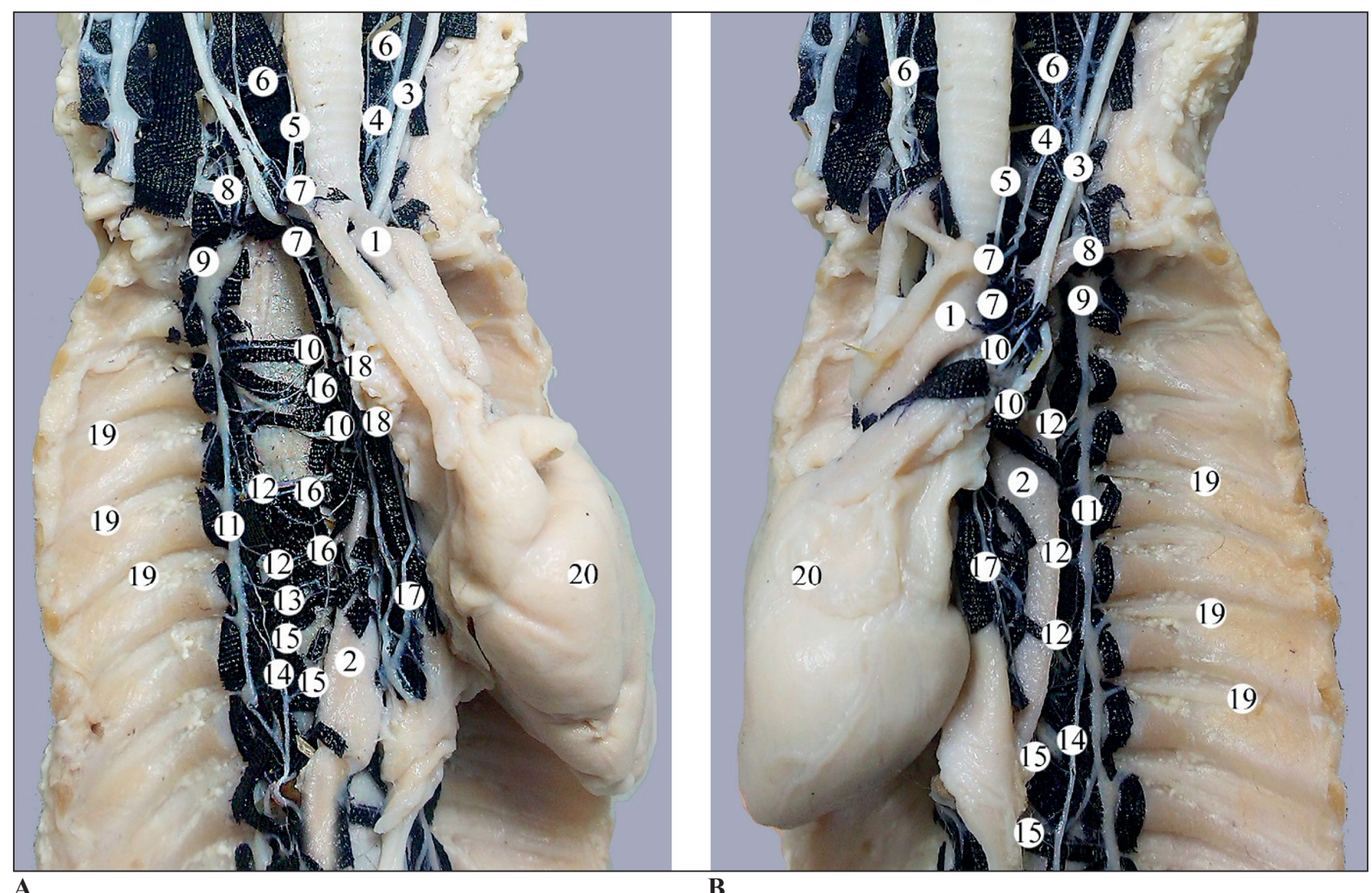

Fig. 1. The nerves of the arch and thoracic aorta of a fetus of $235.0 \mathrm{~mm}$ PCL.

Right (A) and left (B) view. Photo of a macro-preparation. Magnification $1.8^{\times}$.

Legend: 1 - aortic arch; 2 - thoracic aorta; 3 - vagus nerve; 4 - upper cervical heart branches; 5 - recurrent laryngeal nerve; 6 - connecting branch with the aortic nerve (depressor); 7 - branches from the common cardiac trunk to the aortic arch;

8 - subclavian artery; 9 - stellate ganglion; 10 - branches of the vagus nerve to the thoracic aorta; 11 - thoracic part of the sympathetic trunk; 12 - sympathetic branches to the thoracic aortic plexus; 13 - paraaortic plexus; 14 - greater splanchnic nerve;

15 - branches of the greater splanchnic nerve to the thoracic aorta; 16 - vago sympathetic trunks; 17 - esophageal plexus; 18 - branches of the vagus nerve to the pulmonary plexus (lung is removed); 19 - intercostal nerves; 20 - heart.

the aortic arch and pulmonary trunk and enter the cardiac plexus.

In the fetus of $235.0 \mathrm{~mm}$ PCL, as result of the connection of the upper cervical cardiac branches and the upper cervical cardiac nerve, both right and left, a common cardiac trunk is formed, it runs caudally and forms connections with the vagus and recurrent laryngeal nerves (Fig. 1). The common cardiac trunk in the area of the aortic arch is usually divided into anterior and posterior branches, that go to the corresponding walls of the aortic isthmus. Part of the branches continues into the cardiac plexus.

In human fetuses, the medial cervical cardiac nerve begins with $1-3$ branches either from the middle cervical ganglion, or directly from the sympathetic trunk. In the thoracic cavity, the right medial cervical nerve is usually found in the area of branching of the shoulder-head trunk, and the left one between the left common carotid and subclavian arteries.

From the cervical-thoracic (stellate) ganglion of both the right and left sympathetic trunks to the aortic arch branches out the inferior cervical cardiac nerve, which begins with 3-5 branches that encircle the corresponding subclavian artery, and with the help of connecting branches are connected not only with each other, but with the branches of the vagus and recurrent laryngeal nerves and the medial cervical cardiac nerve. In this case, the right lower cervical cardiac nerve passes behind the shoulder-head trunk, and the left one behind the aorta, and enters the cardiac plexus.

In the innervation of the thoracic part of the aorta on both sides mainly take part the branches of the $I^{\text {nd }}-V^{\text {th }}$ thoracic ganglia of the sympathetic trunk, the greater splanchnic nerve and the branch of the vagus nerve (Fig. 2). In isolated cases, in the innervation of the thoracic aorta in fetuses of different ages may take part the branches of the I $^{\text {nd }}-X I^{\text {th }}$ thoracic ganglia of the sympathetic trunk. In this case, the largest value has the I thoracic ganglion, which locates behind the subclavian artery, at the level of the head of the first rib. In most of the studied fetuses, due to the confluence of the first thoracic ganglion with the lower cervical ganglion, a stellate (cervical-thoracic) 


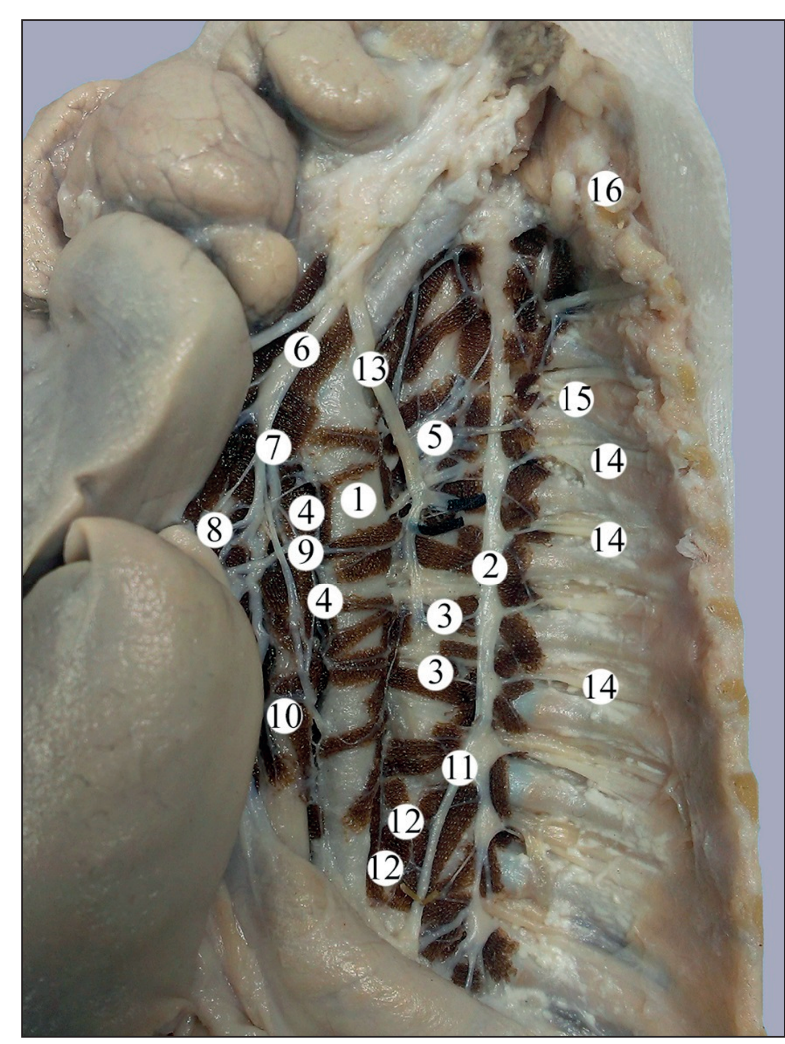

Fig. 2. The nerves of the posterior mediastinum of the fetus of $245.0 \mathrm{~mm}$ PCL. View from the left. Photo of a macro - preparation. Magnification $2.3^{\times}$.

Legend: 1 - thoracic aorta; 2 - thoracic part of the left sympathetic trunk; 3 - sympathetic branches to the thoracic aortic plexus; 4 - connecting branches of the thoracic aortic plexus; 5 - paraaortic plexus; 6 - left vagus nerve; 7 - branches of the vagus nerve to the thoracic aortic plexus; 8 - pulmonary plexus; 9 - connecting branches between the nerve branches of the pulmonary and thoracic aortic plexuses; paraaortic plexus;

10 - esophageal plexus; 11 - greater splanchnic nerve; 12 - branches of the greater splanchnic nerve to the thoracic aorta; 13 - additional semi-paired vein; 14 - intercostal nerves; 15 - intercostal artery of the II $^{\text {nd }}$ intercostal space; 16 - first rib.

ganglion is formed. However, in isolated cases ( $\mathrm{fe}$ tuses of $95.0,165.0,240.0$ and $315.0 \mathrm{~mm} \mathrm{PCL}$ ) the formation of a stellate ganglion due to the confluence of the first and second thoracic ganglia was detected. The internodal branches of the thoracic sympathetic trunk consist of $1-3$ bundles of varying thickness and length. The thoracic cardiac branches are mainly directed from the stellate ganglion, and in isolated cases from the II ${ }^{\text {nd }}, I I I^{\text {rd }}, I V^{\text {th }}$ and $V^{\text {th }}$ thoracic ganglia.

From the thoracic nodes of the right and left sympathetic trunks go the connecting branches. Particularly, from the paramedian edge of the thoracic ganglia, usually from the upper five or six, branch out the connecting branches to the organs, vessels and plexuses of the thoracic cavity, and from the lateral edge or posterior periphery of each thoracic

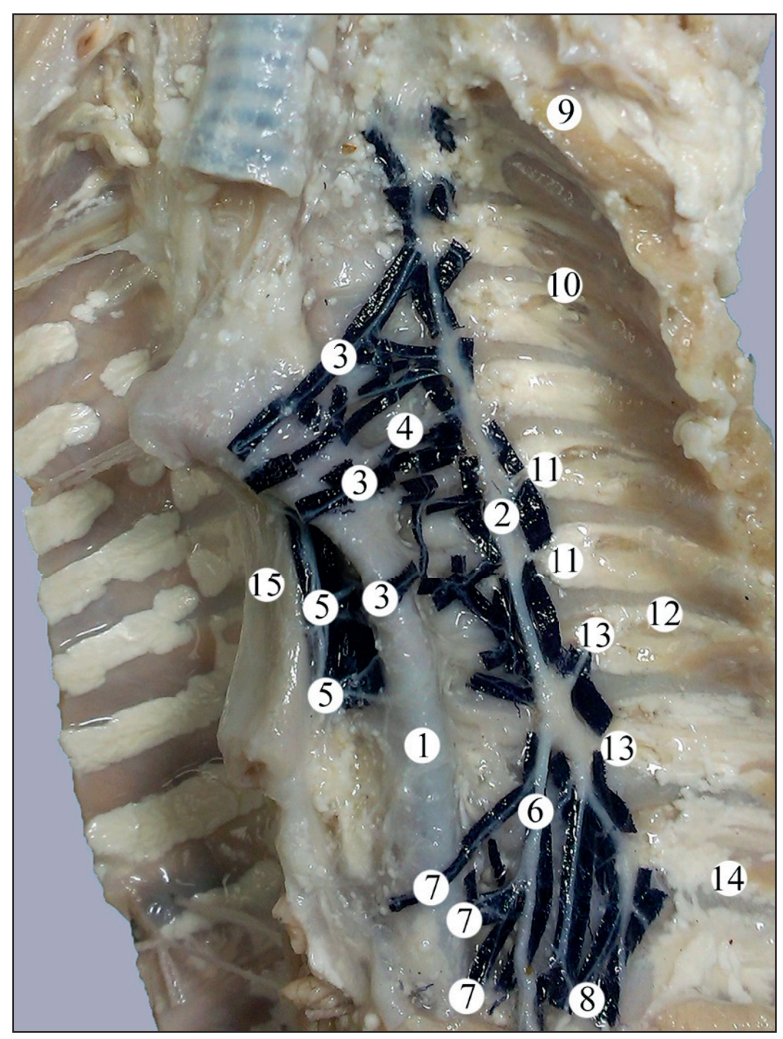

Fig. 3. Nerves of the posterior mediastinum of a fetus of $185.0 \mathrm{~mm}$ PCL. View from the left. Photo of a macro-preparation. Magnification $2.4^{\times}$.

Legend: 1 - thoracic aorta; 2 - left sympathetic trunk; 3 - sympathetic branches to the thoracic aortic plexus; 4 - collateral (bypass) trunk; 5 - branches of the vagus nerve to the thoracic aorta; 6 - greater splanchnic nerve; 7 - branches of the greater splanchnic nerve to the thoracic aorta; 8 - lesser splanchnic nerve; 9 - first rib; 10 - intercostal nerve of the III $^{\text {rd }}$ intercostal space; 11 - connecting branches from the thoracic node of the sympathetic trunk to the $\mathrm{V}^{\text {th }}$ and $\mathrm{VI}^{\text {th }}$ intercostal nerves; 12 - intercostal nerve of the VII ${ }^{\text {th }}$ intercostal space;

13 - connecting branches from the thoracic ganglion of the sympathetic trunk to the VII ${ }^{\text {th }}$ and VIII ${ }^{\text {th }}$ intercostal nerves;

14 - intercostal nerve of the IX ${ }^{\text {th }}$ intercostal space; 15 - esophageal plexus.

ganglion - connecting branches to the intercostal nerves. The interesting fact is that the connecting branches can join not only to the intercostal nerve, which is located at the level of corresponding thoracic ganglion of the sympathetic trunk, but also to the intercostal nerves located above and below (Fig. 3). Connective branches between the thoracic ganglia of the sympathetic trunks and vagus nerve were also found. Herewith, a part of branches, going medially, reaches the walls of the intercostal vessels, azygos vein (on the right), semi-paired and additional semi-paired veins (on the left) and also the thoracic duct. Other branches take part in the formation of the thoracic aortic plexus, which in its upper part has connections with the cardiac plexus, and in the lower part with the abdominal plexus and, also of the plexuses of the 


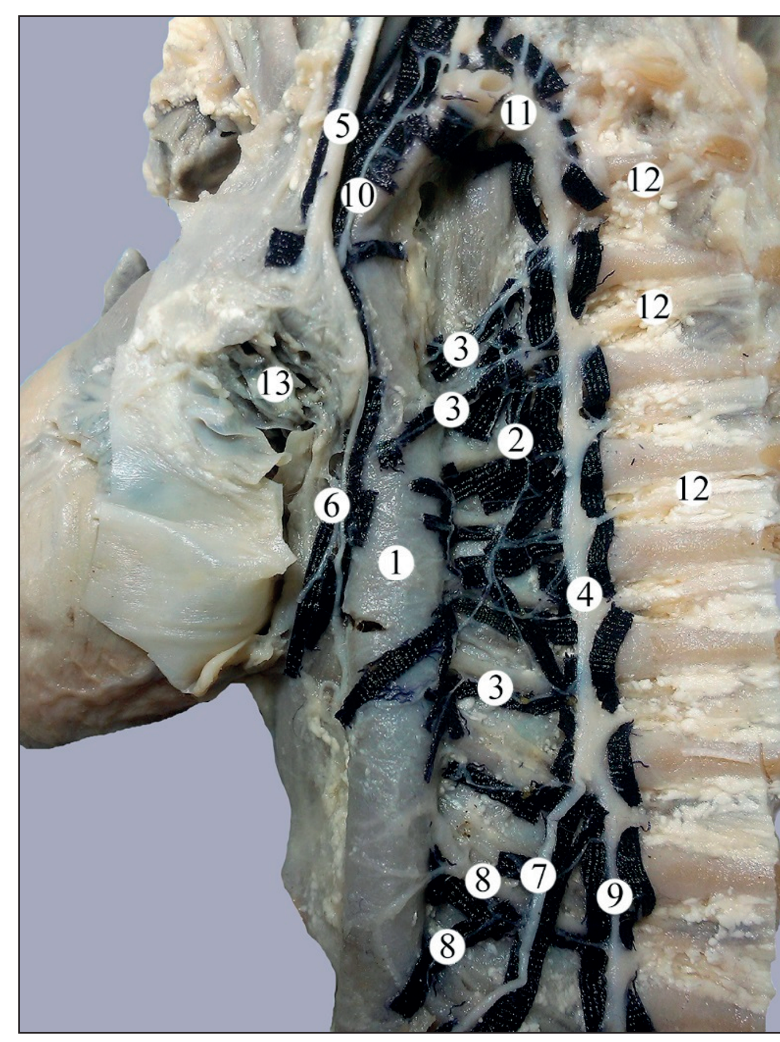

Fig. 4. Nerves of the posterior mediastinum of a fetus of $190.0 \mathrm{~mm}$ PCL. View from the left. Photo of a macro-preparation. Magnification 2.6 ${ }^{\times}$.

Legend: 1 - thoracic aorta; 2 - collateral (bypass) trunk; 3 sympathetic branches to the thoracic aorta; 4 - left sympathetic trunk; 5 -vagus nerve; 6 - esophageal branch of the vagus nerve; 7 - greater splanchnic nerve; 8 - branches of the greater splanchnic nerve to the thoracic aorta; 9 - lesser splanchnic nerve; $10-$ thoracic cardiac nerve; 11 - stellate ganglion; 12 - intercostal nerves; 13 - the root of the left lung (lung is removed)

internal organs, namely esophageal branches - of the esophageal plexus, pulmonary branches - of the pulmonary plexus.

Attention is drawn to the fact that in the paramedian of each thoracic ganglion and of internodal branch of the right and left sympathetic trunks departs from 2 to 6 branches, and some of them go to the thoracic aorta along the posterior intercostal arteries. The other branches are connected by branches of different lengths and thicknesses and form a bypass (collateral) trunk (Fig. 4), in which $2-6$ nerve ganglia are located on the same line.

On 23 preparations of the fetuses of different age $(63.88 \%)$ the nerve branches crossed the anterior intercostal arteries in front and descended at a considerable distance along the lateral wall of the thoracic aorta. These branches then connect to adjacent branches and branches of the greater splanchnic nerve and form the paraaortic plexus. The greater

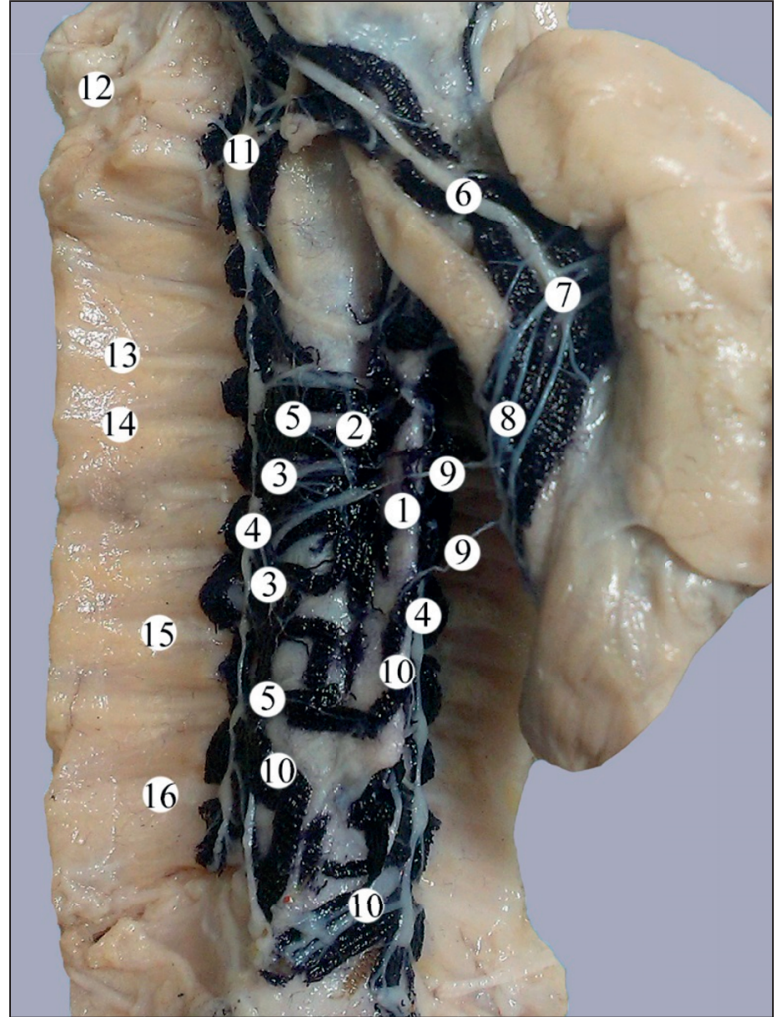

Fig. 5. The nerves of the posterior mediastinum of a fetus of $170.0 \mathrm{~mm}$ PCL.

Photo of a macro-preparation. Magnification 2.4

Legend: 1 -thoracic aorta; 2 - paraaortic plexus; 3 - connecting branches between the nerve branches of the paraaortic plexus; 4 -sympathetic trunks; 5 - sympathetic branches to the thoracic aorta; 6 - vagus nerve; 7 - pulmonary plexus; 8 - esophageal plexus; 9 -branches of the esophageal plexus to the thoracic

aorta; 10 - branches of the greater splanchnic nerve

to the thoracic aorta; 11 - stellate ganglion; 12 - first rib;

13 - intercostal nerve of the $\mathrm{IV}^{\mathrm{th}}$ intercostal space; $14-\mathrm{V}^{\text {th }}$ rib; $15-$ VIII $^{\text {th }}$ rib; $16-\mathrm{X}^{\text {th }}$ rib.

splanchnic nerve usually begins with $2-5$ branches from the ventromedial surface of the $\mathrm{V}^{\text {th }}$ - $\mathrm{XX}^{\text {th }}$ thoracic ganglia, which are located on the lateral surface of the thoracic vertebrae and mainly at the level of the $\mathrm{IX}^{\text {th }}-\mathrm{X}^{\text {th }}$ thoracic vertebrae are connected into a single common trunk. Besides the nerve branches to the thoracic aorta, branches are also directed from the greater splanchnic nerve to the mediastinal part of the parietal pleura, to the abdominal plexus, and to the lesser splanchnic nerve. The latter begins with $2-3$ branches from the IX ${ }^{\text {th }}-\mathrm{XI}^{\text {th }}$ thoracic ganglia. The different skeletotopic level of placement of the greater splanchnic nerve's branches that take part in the innervation of the thoracic aorta was established from $\mathrm{IV}^{\text {th }}$ to $\mathrm{XI}^{\text {th }}$ ribs. From the paraaortic plexus, the nerves both on the right and on the left go to the thoracic aorta, approaching to which the separate nerve branches are divided into two trunks, one of which enters the wall of the thoracic aorta, the other 


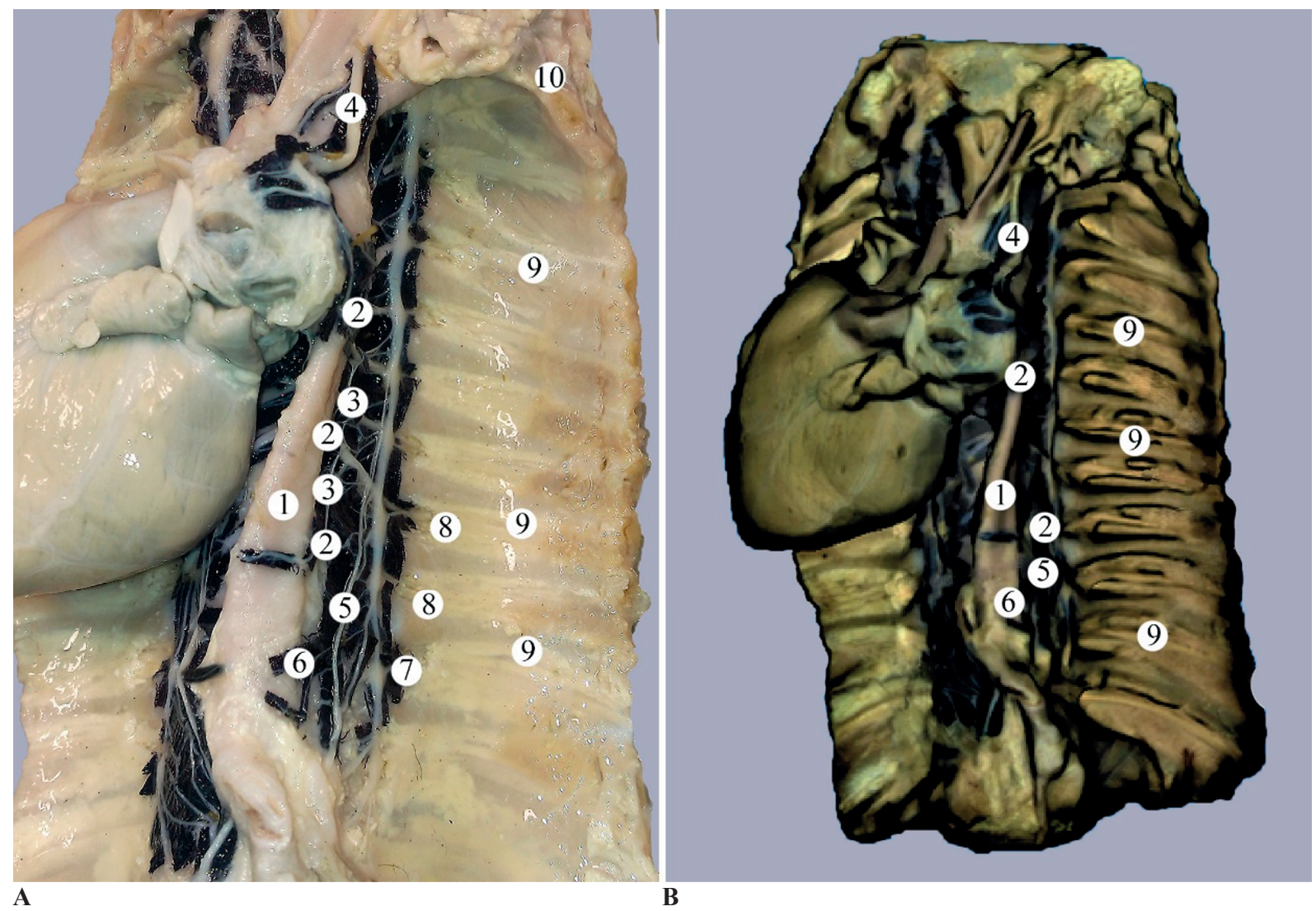

Fig. 6. The nerves of the posterior mediastinum of a fetus of $165.0 \mathrm{~mm}$ PCL. View from the left. Photo of macro-preparation (A), computer three-dimensional reconstruction (B). Magnification 2.2 $2^{\times}(\mathrm{A})$, magnification $1.8^{\times}(\mathrm{B})$.

Legend: 1 - thoracic aorta; 2 - sympathetic branches to the thoracic aorta; 3 - connecting branches of the thoracic aortic plexus; 4 left vagus nerve; 5 - greater splanchnic nerve; 6 - branch of the greater splanchnic nerve to the thoracic aorta; 7 - connecting nerve branch of the left sympathetic trunk and to the VIII intercostal nerve; 8 - intercostal arteries; 9 - intercostal nerves; 10 - first rib.

one goes to the pulmonary or esophageal plexus. As it was mentioned above, a part of the sympathetic branches connects with the branches of the vagus nerve and forms vagal sympathetic trunks on the lateral surface of the thoracic aorta, from which the branches branch out to both, the thoracic aorta and the esophagus. In addition, in one fetus of $170.0 \mathrm{~mm}$ PCL from the esophageal plexus went two branches to the thoracic aorta (Fig. 5).

The vagus nerves throughout the thoracic region give branches to the thoracic aorta, with the formation of the thoracic aortic plexus, which is located on the anterior-lateral walls of the aorta (Fig. 6). The nerves that surround and accompany the branches of the thoracic aorta depart from the thoracic aortic plexus.

We established that in human fetuses of 7-10 months, in comparison with fetuses of 6 months, the number of connecting branches between nerve branches of paraaortic plexus increases.

Herewith, it was found that the sympathetic thoracic pulmonary branches approach the thoracic aorta mainly at the level of the IV $V^{\text {th }}-\mathrm{VI}^{\text {th }}$ intercostal spaces in 19.44\% of cases (7 fetuses) on the right and in $33.33 \%$ of cases (12 fetuses) on the left.

Noteworthy are the data obtained by us during macro-micro-preparation of the nerves of the arch and thoracic aorta in human fetuses of 4-10 months. Thus, the sources of innervation of the aortic arch in the fetal period of human ontogenesis are the cervical cardiac branches of the vagus nerves, cervical cardiac nerves and single branches of the upper three or four thoracic ganglia of the sympathetic trunks.

The obtained results on the topographic anatomical interrelations of the left recurrent laryngeal nerve and the aortic arch correspond with the data of individual authors ${ }^{13-16}$.

According to our studies, the innervation of the thoracic aorta is provided by the branches of the thoracic aortic plexus, collateral trunk, and branches of the paraaortic plexus, which is located between the sympathetic trunk and the thoracic aorta on both sides. The vagus nerves throughout the thoracic region give branches to the thoracic aorta with the formation of the thoracic aortic plexus, from which depart the nerves that surround and accompany the 
branches of the thoracic aorta, which corresponds with the research ${ }^{17,18}$.

Our studies showed that in the dynamics of the fetal period of ontogenesis there is a bilateral asymmetry in the structure and formation of plexuses of the thoracic aorta. The nerve branches going to the thoracic aorta from various sources enter its wall, either together with blood vessels or in isolation.

The obtained data on fetal variant anatomy of the nerves of the arch and thoracic aorta deserve special attention. Particularly, in the fetus of $235.0 \mathrm{~mm}$ PCL it was described the formation of a common cardiac trunk, result of the confluence of the upper cervical cardiac branches and the upper cervical cardiac nerve, which in the aortic arch was divided into anterior and posterior branches. In another fetus of $170.0 \mathrm{~mm}$ PCL, two nerve branches from the esophageal plexus went to the thoracic aorta.

The results of our study offered data on the participation, topography and number of branches from the thoracic ganglia of the right and left sympathetic trunks in the innervation of the thoracic aorta. Thus, from each thoracic ganglion and internodal branch of the right and left sympathetic trunks depart 2-6 branches, some of which go to the thoracic aorta along the posterior intercostal arteries, and other branches are connected by branches forming a bypass trunk. At the end of the fetal period of human ontogenesis, an increase in the number of connecting branches between the nerve branches of the paraaortic plexus was observed.

The sympathetic thoracic pulmonary branches approach the thoracic aorta mainly at the level of the IV ${ }^{\text {th }}-V I^{\text {th }}$ intercostal spaces in $19.44 \%$ of cases on the right and in $33.33 \%$ of cases on the left.

The study revealed a quantitative predominance of branches of the sympathetic trunk on the thoracic aorta and diaphragm, and branches of the vagus nerve - on the esophagus.

Due to $3 \mathrm{D}$ reconstruction, we were able to determine and describe the spatial interrelations of the thoracic aortic nerves in fetuses of different ages.

In the future, it would be desirable to establish patterns of functional variation of nerves, plexuses and anastomoses in the thoracic aorta, as well as of the structural organization of the adventitious plexus of the thoracic aorta during the fetal period of human ontogenesis.

\section{Conclusions}

The innervation of the aortic arch is provided by the cervical cardiac branches of the vagus nerves, the cervical cardiac nerves and the branches of the upper three or four thoracic ganglia of the sympathetic trunks.

In human fetuses, between the right and left sympathetic trunks and the thoracic aorta, in addition to the intermediate plexus or collateral trunk, a paraaortic plexus is determined, the branches of which are involved in the innervation of the thoracic aorta.

The bilateral asymmetry of the structure and topography of the plexuses of the thoracic aorta was established.

At the end of the fetal period of human ontogenesis, the number of connecting branches between the nerve branches of the paraaortic plexus increases.

\section{Author Contributions:}

Conceptualization, G.S. and T.K.; methodology, I.L.; software, V.V.; validation, I.K. and V.V.; formal analysis, R.K.; investigation, G.S.; resources, G.S.; data curation, T.K.; writing-original draft preparation, G.S.; writing-review and editing, G.S., T.K. visualization, G.S.; supervision, T.K.; project administration, G.S. and T.K.

All the authors have read and agreed with the final version of the article.

\section{Compliance with Ethics Requirements:}

"The authors declare no conflict of interest regarding this article"

"The authors declare that all the procedures and experiments of this study respect the ethical standards in the Helsinki Declaration of 1975, as revised in 2008(5), as well as the national law. Informed consent was obtained from all the patients involved in the study"

"No funding for this study"

\section{References}

1. Wittekindt B, Schloesser R, Doberschuetz N, et al. Epidemiology and outcome of major congenital malformations in a large German county. Eur J Pediatr Surg. 2019; 29(3): 282-289.

2. Kirby RS. The prevalence of selected major birth defects in the United States. Semin Perinatol. 2017; 41(6): 338-344.

3. Li S, Wen H, Liang M, et al. Congenital abnormalities of the aortic arch: revisiting the 1964 Stewart classification. Cardiovasc Pathol. 2019; 39: 38-50.

4. Calero A, Illig KA. Overview of aortic aneurysm management in the endovascular era. Semin Vasc Surg. 2016; 29(1-2): 3-17.

5. Coelho SG, Almeida AG. Marfan's syndrome revisited: From genetics to the clinic. Rev Port Cardiol (Engl Ed). 2020; 39(4): 215-226.

6. Rurali E, Perrucci GL, Pilato CA, Pini A, Gaetano R, Nigro P, Pompilio G. Precise therapy for thoracic aortic aneurysm in Marfan syndrome: a puzzle nearing its solution. Prog Cardiovasc Dis. 2018; 61(3-4): 328-335. 
7. Hagerty T, Geraghty P, Braverman AC. Abdominal aortic aneurysm in Marfan syndrome. Ann Vasc Surg. 2017; 40: 294. e1-294.e6.

8. Conway AM, Qato K, Anand G, Mondry L, Giangola G, Carroccio A. Endovascular abdominal aortic aneurysm repair in patients with Marfan syndrome. Vascular. 2020; 28(1): 48-52.

9. Elefteriades JA, Farkas EA. Thoracic aortic aneurysm clinically pertinent controversies and uncertainties. J Am Coll Cardiol. 2010; 55(9): 841-57.

10. Adriaans BP, Wildberger JE, Westenberg JJM, Lamb HJ, Schalla S. Predictive imaging for thoracic aortic dissection and rupture: moving beyond diameters. Eur Radiol. 2019; 29(12): 6396-6404.

11. Kenny D, Hijazi ZM. Coarctation of the aorta: from fetal life to adulthood. Cardiol J. 2011; 18(5): 487-95.

12. Le Noble F, Fleury V, Pries A, Corvol P, Eichmann A, Reneman RS. Control of arterial branching morphogenesis in embryogenesis: go with the flow. Cardiovasc Res. 2005; 65(3): 619-28.

13. Fürniss HE, Hummel J, Stiller B, Grohmann J. Left recurrent laryngeal nerve palsy following aortic arch stenting: A case report. World J Cardiol. 2019; 11(12): 316-321.
14. Furukawa T, Otsuki N, Tomotsu M, et al. Left non-recurrent inferior laryngeal nerve in a patient with right-sided aortic arch and aberrant left subclavian artery. Auris Nasus Larynx. 2021; 48(2): 317-321.

15. Masuoka H, Miyauchi A, Higashiyama T, Yabuta T, Kihara M, Miya A. Right-sided aortic arch and aberrant left subclavian artery with or without a left nonrecurrent inferior laryngeal nerve. Head Neck. 2016; 38(10): E2508-11.

16. Willson TJ, Stevens J, Salinas N, Brennan JA. Aberrant position of nonrecurrent inferior laryngeal nerve: Report of 3 cases and a review of the literature. Ear Nose Throat J. 2016; 95(6): E26-31.

17. Molin DG, Poelmann RE, DeRuiter MC, Azhar M, Doetschman T, Gittenberger-de Groot AC. Transforming growth factor beta-SMAD2 signaling regulates aortic arch innervation and development. Circ Res. 2004; 95(11): 1109-17.

18. Karakaya C, Goktas S, Celik M, Kowalski WJ, Keller BB, Pekkan K. Asymmetry in mechanosensitive gene expression during aortic arch morphogenesis. Sci Rep. 2018; 8(1): 16948. 